\title{
OS LIMITES NO NOVO CONSTITUCIONALISMO LATINO- AMERICANO DIANTE DE UMA CONJUNTURA DE RETROCESSOS
}

\section{THE LIMITS IN THE NEW LATIN AMERICAN CONSTITUTIONALISM \\ THROUGH A BACKSPACE CONJUNCTURE}

\author{
Gladstone Leonel Júnior \\ Doutor em Direito \\ Faculdade de Direito da \\ Universidade Federal Fluminense (UFF) \\ Brasil \\ gleoneljr@gmail.com
}

\section{Resumen}

O novo constitucionalismo latino-americano surge com um tom combativo e popular na realização do debate constitucional e alteração das estruturas de poder do Estado no início do século XXI. No entanto, a conjuntura de retrocessos políticos, alimentadas por golpes de Estado, iniciadas na segunda década do século XXI tornam perceptível as limitações políticas no cenário em que foi forjado o novo constitucionalismo latino-americano.

PALAVRAS-CHAVE: Novo Constitucionalismo Latino-Americano; retrocessos políticos; limites. 


\begin{abstract}
The new Latin American constitutionalism appears with a combative and popular tone in the accomplishment of the constitutional debate and alteration of the power structures of the State in the beginning of the 21 st century. However, the conjuncture of political setbacks, promoted by coups d'état, which began in the second decade of the 21 st century, makes it possible to perceive the political limitations in the scenario in which the new Latin American constitutionalism was forged.
\end{abstract}

KEYWORDS: New Latin American constitutionalism; political setbacks; limits. 


\section{INTRODUÇÃO}

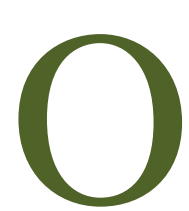

debate constitucional que permeou, e ainda permeia, diversos juristas e sociólogos/as da América

Latina e Europa no último período, conhecido por parte da doutrina como o Novo Constitucionalismo LatinoAmericano passa por novos desafios conjunturais. Além disso, alguns limites dessa recente construção constitucional tornaram-se mais evidentes.

Para além da retomada dos programas políticos neoliberais em vários países da região como no Brasil, na Argentina, no Paraguai, dentre outros, há ainda um retorno aos processos golpistas que desrespeitam o próprio andamento democrático, e requentam as ondas históricas de golpes políticos na América Latina.

Diante desse cenário, cabe refletir até que ponto os países que modificaram suas estruturas constitucionais a partir de determinadas rupturas políticas tem condições de levar adiante o processo transformador que se propuseram. Bolívia, Venezuela e Equador são os exemplos mais eloqüentes desse dilema, dentre os quais convivem com os limites transformadores intraconstitucionais, a pressão imperialista, e da própria elite econômica interna, que tentam desestabilizar os seus processos políticos.

Em momentos de crise, em suas mais diversas dimensões, seja política, econômica ou até mesmo de valores, que o imperialismo aprofunda a violência, faz alianças internas e expande seus tentáculos com o propósito de hegemonizar processos políticos, os quais possuem pouca ingerência. As redes de apoio de outrora, como a UNASUL - União de Nações SulAmericanas, a CELAC - Comunidade dos Estados Latino-americanos e Caribenhos -, o MERCOSUL - Mercado Comum do Sul, a ALBA - Aliança Bolivariana para os Povos da Nossa América - estão mais fragilizadas, em razão da leva de governos conservadores que ora avançam sobre os países latino-americanos.

Mesmo com as limitações, decorrentes dos processos históricos de cada país, o Novo Constitucionalismo Latino-Americano ainda tende a cumprir papéis fundamentais. Isso não só na formulação e na proposição de caminhos inovadores para o andamento de projetos políticos progressistas, mas, sobretudo, resistir à ofensiva de uma conjuntura de retrocessos políticos, a qual também busca engolir essas experiências. 
2. OS CAMINHOS DO NOVO CONSTITUCIONALISMO

\section{LATINO-AMERICANO}

A partir de 1999, sobretudo após a implementação dos programas neoliberais em praticamente todos os Estados da América, surgiram governos provenientes de uma resistência popular, a qual lutou contra os efeitos dessas medidas de austeridade que atingiam grande parcela da população. Em pouco mais de uma década, mais de 10 países se inclinaram a esquerda ou a centro-esquerda elegendo presidentes populares. Dentre os exemplos mais emblemáticos podemos destacar: um militar revolucionário na Venezuela (Hugo Chávez), um militante operário (Lula) e uma lutadora contra a ditadura militar no Brasil (Dilma Rousseff), um sindicalista cocalero na Bolívia (Evo Morales), um economista anti-imperialista no Equador (Rafael Correa), uma lutadora contra ditadura militar no Chile (Michelle Bachelet), um guerrilheiro tupamaro no Uruguai (Pepe Mujica), um casal de peronistas de esquerda na Argentina (Nestor e Cristina Kirchner), um padre da teologia da libertação no Paraguai (Fernando Lugo), etc. (LEONEL JÚNIOR, 2015, p. 59).

Diante de um ambiente político combativo na América Latina, o qual possibilitou a eleição de governos com esse perfil, efetivaram-se alguns princípios constitucionais, que antes não passavam de "letra morta" da lei, principalmente a efetivação de direitos sociais, e nasceram novas Constituições. Algumas delas, provenientes de rupturas políticas capazes de contribuir para reformulações institucionais profundas como as Constituições da Venezuela (1999), do Equador (2008) e da Bolívia (2009).

Essa movimentação político-jurídica do debate constitucional, que chamamos de Novo Constitucionalismo LatinoAmericano, apresenta mudanças em seus aspectos formais e também em seus aspectos materiais-estruturantes.

Ao observar esses aspectos formais, nota-se que os processos constituintes instituem trajetos que contam com uma maior participação popular. O povo passa a assumir um maior protagonismo ao ser convocado para decidir a respeito da solicitação ou não de um processo constituinte. Mas, não parou por aí!

Além dos constituintes contarem com uma participação popular ativa na formulação dos conteúdos, que ocorriam em diversas regiões do país, como no caso da Bolívia, havia a necessidade de aprovação de um referendo popular para confirmar ou não o conteúdo constitucional proposto. Ali, de fato, verificava-se a ativação do poder constituinte originário. 
No que tange as emendas constitucionais nesses países, ou seja, instrumentos de exercício do poder constituinte derivado, devem passar pelo crivo popular para sua efetivação. Assim, não se modifica o corpo constitucional sem o aval do povo, diferentemente do que ocorre nos dias atuais brasileiro, pós-golpe de 2016, com mudanças constitucionais a toque de caixa, desconsiderando a população em geral.

Os autores Roberto Viciano Pastor e Rubén Martínez Dalmau trazem a originalidade, a amplitude das normas, a complexidade aliada a uma linguagem simples e a rigidez como elementos formais comuns às Constituições caracterizadas nesse contexto do novo constitucionalismo latino-americano (2010, p. 14). Esses elementos contribuem para uma maior popularização do corpo constitucional nos países que passaram recentemente pelos processos constituintes.

Já o português Boaventura de Sousa Santos trata essas mudanças como um constitucionalismo experimental e transformador, o qual aponta para caminhos anticapitalistas e anticolonialistas (2010, p. 77).

De toda forma, "não basta dogmaticamente prever rol de direitos.

\footnotetext{
1“A Bolívia converteu-se, assim, no terceiro país que conseguiu vencer o analfabetismo na América Latina, depois de Cuba, em 1961, e da Venezuela, com apoio cubano, em 2005. Os números: 819.417
}

Afirmá-los formalmente é reproduzir a mera bandeira liberal. Há uma necessidade de se introduzir mudanças profundas na estrutura constitucional para permitir a viabilidade e execução desse rol de direitos” (LEONEL JÚNIOR, 2015, p. 122).

No que tange aos aspectos materiais-estruturantes, não resta dúvida que a partir da forma se assegurou um maior fluxo democrático na garantia de direitos. Observou-se com isso, um fortalecimento das pautas relacionadas às questões de gênero e étnico-raciais. Como uma engrenagem política puxa a outra, os índices de desigualdade social e analfabetismo, de acordo com a UNESCO ${ }^{1}$, despencaram nesse período com políticas decorrentes de uma reestruturação institucional tendo por base a Constituição. Ademais, as políticas de retomada dos setores estratégicos na economia foram fundamentais para garantir subsídios aos Estados no fomento de políticas públicas de crescimento.

Houve um grande processo de redistribuição da riqueza social em países como o Brasil, a Venezuela, o Equador e a Bolívia. Isso gerou uma ampliação das classes médias (classe trabalhadora empregada) e um aumento de sua

pessoas alfabetizadas em um universo de 824.101 analfabetos detectados (99,5\%); 28.424 pontos de alfabetização criados nos nove departamentos da Bolívia" (grifo nosso). (ROJAS, 2008). 
capacidade de consumo. Com isso, ocorreu uma drástica diminuição da desigualdade social, algo que não se realizava há muitos anos.

Figura 01 - Declínio da desigualdade na América Latina por país 2000-2010 (\% de mudança anual do coeficiente de Gini) históricas desses países em temas como: descolonização, plurinacionalidade, democracia, jurisdições entre outros.

Não restam dúvidas que a América Latina assumiu uma maior autonomia frente à sanha imperialista e um maior exercício da

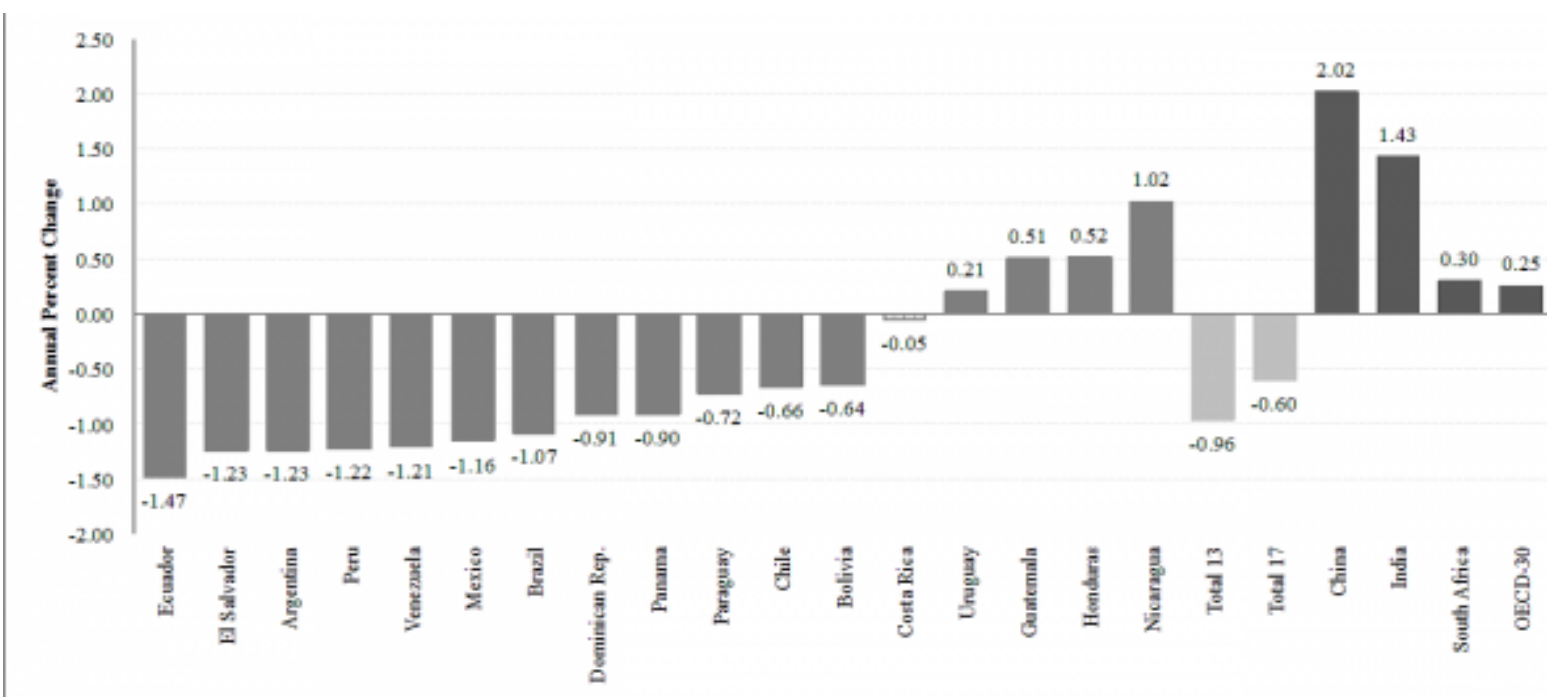

FONTE: Cálculos baseados em dados do SEDLAC (CEDLAS and The World Bank), Março 2012

(http://sedlac.econo.unlp.edu.ar/eng/)

soberania de seus Estados, desde a fundação dos mesmos, nessa mais recente onda de governos progressistas.

Importante destacar que as As propostas pós-neoliberais dos mudanças também incorporam medidas materiais-estruturantes, visto que os elementos tendem a alterar diversos pontos relacionados a construção das estruturas de poder (LEONEL JÚNIOR, 2015, p. 125). Basta observar as transformações decorrentes de necessidades sócio- 
então estavam nas mãos da iniciativa privada.

O rearranjo de grupos e forças políticas ao construir uma unidade permitiu que houvesse um ascenso dos movimentos sociais e populares, os quais passaram, em parte, a assumir as tarefas do Estado. Nessa lógica conseguiram frear e retroceder as políticas neoliberais. É o que Álvaro Garcia Linera chamará de presença plebéia (2008). Os processos constituintes, como já citados, são exemplos evidentes de mudanças políticas concretas com a real participação popular.

Além disso, nesse período, algumas associações, sindicatos e outros espaços de participação como os conselhos foram fortalecidos em determinados Estados. A sociedade civil passou também a se organizar na defesa dos avanços garantidos pelos governos populares. Na Bolívia, em certo período, as Juntas de Vizinhos constituíram instrumento importante de participação e luta política; na Venezuela, os Conselhos Populares contribuem de maneira central para o enraizamento da Revolução Bolivariana no seio da sociedade venezuelana.

Todo esse contexto na América Latina contribuiu para uma espécie de articulação progressista e, em alguns casos,

\footnotetext{
${ }^{2}$ Trata-se de um acrônimo que faz menção aos países membros fundadores (BRICS: Brasil,
}

revolucionária, a nível continental. Caracterizou-se um momento em que, nós, latino-americanos deixamos a figura de capacho e subserviente às grandes potencias político-econômicas e assumimos um protagonismo jamais visto até então. Nessa toada que surgiram a CELAC, a UNASUL, a ALBA, o Banco do Sul, os BRICS ${ }^{2}$, a Telesul, dentre outras iniciativas de fortalecimento de um campo político do sul, o qual ousava desafiar os séculos de dependência a que estava submetido.

Um efeito concreto da influência dessa onda política e da força da articulação entre os países ocorreu, por exemplo, em 2008, quando houve uma tentativa de desestabilização política interna na Bolívia: o Estado tinha dificuldades em controlar os Departamentos da Meia Lua (Pando, Santa Cruz, Tarija e Beni), ou seja, quatro dos nove existentes. A Bolívia somente superou essa tensão com o apoio irrestrito dos governos progressistas da América Latina na legitimação de suas ações.

Todas essas mudanças em pouco mais de uma década é algo a ser destacado, jamais deixado de lado.

Rússia, Índia, China e África do Sul), que juntos formam um grupo político de cooperação. 
3. OS LIMITES POSTOS EM PERÍODOS DE RETROCESSOS CONJUNTURAIS

Depois desse período de progressos conjuntos na América Latina, esse avanço se deteve. Em alguns casos retrocedeu. Está em curso a reconstituição das velhas elites, as quais passam a reassumir o controle da gestão pública.

Todavia, isso não quer dizer que as Constituições Populares latino-americanas perderam a importância! Muito pelo contrário, elas representam um pacto social difícil de ser desatado por essas elites que buscam retomar o poder dos Estados. Em regra, os países que passaram pelo crivo de um processo constituinte popular, ainda mantêm um projeto político progressista em andamento como Venezuela, Bolívia e Equador, sobretudo, por terem forjado nesse processo uma sociedade civil mais combativa e organizada.

Contudo, ainda sim as contradições e os limites são inerentes a esses processos que não podem parar, quando se almeja a construção do poder popular na América Latina.

Diante do quadro atual, o primeiro gargalo trazido por essas contradições é a econômica. Talvez, devido ao profundo grau de miséria e a grande desigualdade social nos países latino-americanos, foi dada pouca importância a mudança da matriz econômica. No entanto, ao se tratar de um processo de ruptura, revolucionário, é fundamental a base econômica para alavancar isso.

Os setores populares da sociedade devem construir um lastro de confiança a partir da questão econômica, desenvolvendo a produção com estabilidade e não causando mal estar na população (LENIN, 1977).

Alguns governos progressistas potencializaram o bloco conservador, não sendo progressista com suas políticas econômicas. $\mathrm{O}$ fato de ter que governar para todos não poderia significar a entrega dos recursos que debilitassem sua própria base social, ou seja, aquela que sai às ruas para defender o projeto popular. O ajuste fiscal ocorrido no Brasil, no início do segundo mandato do governo de Dilma Rousseff, foi um grande exemplo do cometimento desse tipo de erro ao fragilizar a sua base social com medidas impopulares. Alguns autores atribuem essas debilidades ao constatarem a reprodução de práticas desenvolvimentistas, que diferem muito pouco do que foi realizado nos governos conservadores, afetando também a base social popular. Algo apontado por Salvador Schavelzon (2017), como uma das motivações para o fim dos ciclos progressistas. 
Por outro lado, mesmo com os mecanismos de pluralismo econômico salientados nas Constituições, como a boliviana, poderíamos imaginar que os governos progressistas deveriam acabar com os mercados e socializar os meios de produção? Certamente não! Pois, não se trata de mera vontade do governante, tampouco isso se dá por simples assinatura de um decreto. Um processo revolucionário para obter êxito, não pode ser isolado, ela deve avançar pelo continente e internacionalizar-se, caso contrário não há razão para ser considerado revolucionário. Assim, a probabilidade de sucesso dos empreendimentos econômicos tende a ser maior extrapolando os limites do EstadoNação e com maior capacidade de subverter a mera reprodução do capital de forma dependente e submissa a uma divisão internacional do trabalho já dada.

Notou-se ainda, que politicamente ocorreu uma integração importante entre os países da região contribuindo para $\mathrm{o}$ fortalecimento de uma identidade latinoamericana. No entanto, a integração política não é o suficiente, quando a economia está limitada às fronteiras do Estado-Nação.

Esse é um grande desafio a ser realizado, uma integração econômica latino-americana. $\mathrm{O}$ vice-presidente da Bolívia, Álvaro Garcia Linera, (2016) apresenta um desafio ainda maior, convergindo com o sonho de Bolívar: o de construir um Estado Continental Plurinacional capaz de respeitar as estruturas nacionais de cada país, porém manter um segundo piso de instituições continentais em todos os setores, o que consistiria em um grande desafio para o século XXI.

Outro ponto a ser destacado como limitante dos avanços populares, nessa mais recente onda progressista, é a distribuição da riqueza na sociedade sem a politização social decorrente dessa medida. $\mathrm{O}$ que temos hoje em países como Argentina e Brasil são pessoas que não associam os novos direitos e a maior capacidade de consumo a um projeto político, mas imaginam que isso se deve ao mérito individual das sociedades de consumo. Ao insistir nesse tipo de política, não se cria um sentido comum concebido por meio de um projeto.

Quando temos uma pessoa pobre formada em medicina no Brasil, não se trata simplesmente de mérito. Se não existissem programas de governo como o Prouni (Programa Universidade para Todos) ou Reuni (Reestruturação e Expansão das Universidades Federais Brasileiras), muito dificilmente pessoas de um extrato social mais baixo teriam condições de ingressar. Trata-se de um projeto político, que não se comunicou bem, visto que não politizou as 
pessoas que acessavam seus mecanismos de inclusão.

Ademais, de nada adianta reproduzir os velhos esquemas morais, a partir de uma cultura de massa incapaz de avançar sob o status quo. $\mathrm{O}$ processo revolucionário também deve perpassar por uma revolução cultural capaz de acessar, democratizar os meios de comunicação e ter condições de construir esse sentido comum nas pessoas. Assim, ganha estofo e cresce a importância da comunicação comunitária, das representações de associação de bairro, dos difusores da cultura popular, dos dirigentes estudantis entre outros setores da sociedade civil organizada, fundamentais para $\mathrm{o}$ processo revolucionário.

Essa articulação e controle social permitem, inclusive, um aprimoramento do Estado que deverá agir de forma cada vez mais transparente e verdadeira com o povo.

Por fim, outra questão profundamente tratada e considerada central no debate do novo constitucionalismo latino-americano é a democracia. Esse é um grande desafio para a manutenção de avanços políticos dentro da América Latina. Desde 2009, alguns países da região passaram a sofrer golpes, inclusive parlamentares, interferindo na qualidade e avanço democrático no continente. Vide os episódios ocorridos em Honduras, no Paraguai e no Brasil.
No caso de Venezuela e de Bolívia, os avanços democráticos foram significativos a ponto dos países romperem com as velhas estruturas, amparadas por novas Constituições, e forjarem ciclos inovadores por meio de um processo revolucionário. Como já salientado, na Venezuela se tem o estimulo á democracia participativa através dos Conselhos Comunais, já na Bolívia, o reconhecimento da democracia comunitária representa um avanço ao que existia até então. Contudo, diferentemente de quando se triunfa na Revolução armada, nos casos citados é necessário conviver com o adversário, mesmo que a vitória sobre eles tenha sido política, moral e de narrativa.

Logo, nos deparamos com uma nova questão na caracterização do processo revolucionário. As revoluções personificam o espírito das épocas e surgem das próprias pessoas. Todas essas revoluções, atuais ou anteriores, sempre necessitaram de líderes, os quais devem obediência ao pacto social realizado nas constituintes populares. $\mathrm{O}$ grande desafio desses processos é dar uma continuidade da construção subjetiva às lideranças revolucionárias, não caindo no personalismo fajuto, para manterem a perspectiva histórica do que se constrói.

De repente, a tentativa de constituição de formas decisórias coletivas, sem ignorar as lideranças, permita dar andamento a esse processo, o qual pode ser estimulado pela 
própria base do novo constitucionalismo latino-americano e dê continuidade à formação dessas lideranças populares na democracia.

\section{CONSIDERAÇÕES FINAIS}

Não nos cabe, simplesmente, sermos pessimistas em relação ao futuro em decorrência dos retrocessos gerais, que iniciaram aproximadamente na metade da década de 10 do século XXI. Até porque a história nunca foi marcada por um processo linear e contínuo, mas como dizia Karl Marx (1984) o processo revolucionário é pendular, marcado por ondas, o homem e a mulher não o realizam simplesmente quando querem.

O fato de ser um processo comporta recuos, mas também, em algum momento, haverá uma próxima onda. Não se pode precisar quando, mas os setores populares devem estar preparados para a chegada desse próximo pêndulo ou dessa nova onda. A autocrítica é fundamental para a verificação das falhas decorrentes dos últimos períodos de hegemonia do bloco progressista. Mesmo com todo o retrocesso conjuntural e as contradições inerentes aos processos, Cuba ainda permanece firme, da mesma forma que Venezuela, Bolívia e Equador, que ainda possuem o suporte político baseado e construído nas concepções do novo constitucionalismo latino-americano.

O Novo constitucionalismo latinoamericano passa para uma etapa de resistência. As Constituições provenientes da sua concepção, para além de construírem uma perspectiva constitucional mais participativa, popular e emancipadora, servem agora como instrumentos que resistem aos ataques dos setores neoliberais, os quais buscam desmantelá-las. Não interessa a esses setores, Constituições fortes, democráticas e populares, por isso não interessa a eles o que propõe o novo constitucionalismo latino-americano. Por esse motivo, essas Constituições talvez nunca tenham sido tão importantes como nesse momento de resistência.

Os setores da sociedade ligados a pauta neoliberal não possuem grandes projetos a não ser o de restaurar os privilégios que sempre tiveram. O tempo histórico está do lado do povo, os quais compreendem que as ondas da história não surgem por acaso, mas são provenientes da luta que ainda a de ser empreendida.

\section{Referencias}

GARCIA LINERA. Álvaro. La potencia plebeya. Acción colectiva e identidades indígenas, obreras y populares en Bolivia. La Paz: Prometeo libros/Clacso, 2008. 
Reunión de ministros de

Cultura de la Comunidad de Estados

Latinoamericanos y Caribeños

(CELAC). Vicepresidencia Del

Estado Plurinacional de Bolívia. La

Paz, 2016. Disponível em:

https://www.vicepresidencia.gob.bo/

Participacion-del-vicepresidente-del-

Estado-Alvaro-Garcia-Linera-en-la.

Acesso em: 03 mar. 2017.

LENIN. Wladimir Ilytch. As Tarefas imediatas do Poder Soviético. 1918. Editorial Avante, Edições Progresso: Lisboa, 1977. Disponível em: http://marxists.anu.edu.au/portugues/l enin/1916/imperialismo/index.htm.

Acesso em 16 mar. 2017.

LEONEL JÚNIOR, Gladstone. O

novo constitucionalismo latino-

americano: um estudo sobre a

Bolívia. Rio de Janeiro: Lumen Juris, 2015.

MARTÍNEZ DALMAU, Rubén; VICIANO PASTOR, Roberto. ¿Se

puede hablar de un nuevo

constitucionalismo latinoamericano

como corriente doctrinal

sistematizada? In: Nuevas tendencias

del derecho constitucional en

América Latina, VIII Congreso

Mundial de la Asociación

Internacional de Derecho
Constitucional: constituciones y

principios, México, dez. 2010a.

Disponível em:

<www.juridicas.unam.mx/wccl/pone ncias/13/245.pdf>. México. Acesso

em: 30 abr. 2012.

MARX. Karl. O 18 de Brumário de Louis Bonaparte. 1851-1852. Trad. José Barata-Moura e Eduardo Chitas. Editorial Avante, Edições Progresso: Lisboa, 1984. Disponível em: https://www.marxists.org/portugues/ marx/1852/brumario/index.htm.

Acesso em 16 mar. 2017.

ROJAS, R. Bolívia é o terceiro país da América Latina Livre de analfabetismo. La Jornada. La Paz, 2008. Disponível em:

http://www.cartamaior.com.br/?/Edit oria/Internacional/Bolivia-e-o-3\% B0pais-da-America-Latina-livre-deanalfabetismo\%0D\%0A/6/14577. Acesso em: 03 mar. 2017.

SCHAVELZON, Salvador. El fin de ciclo progresista sudamericano $¿ \mathrm{Ha}$ sido derrotado el imaginario político de la izquierda?. Nueva Sociedad. Democracia y Política en América Latina. Buenos Aires, 2017.

Disponível em:

http://nuso.org/articulo/el-fin-de- 
ciclo-progresista-sudamericano/.

Acesso em: 03 mar. 2017.

SOUSA SANTOS, Boaventura.

Refundación del Estado en América

Latina: perspectivas desde una

epistemología del Sur. La Paz: Plural

Editores, 2010. 